Provided for non-commercial research and education use. Not for reproduction, distribution or commercial use.

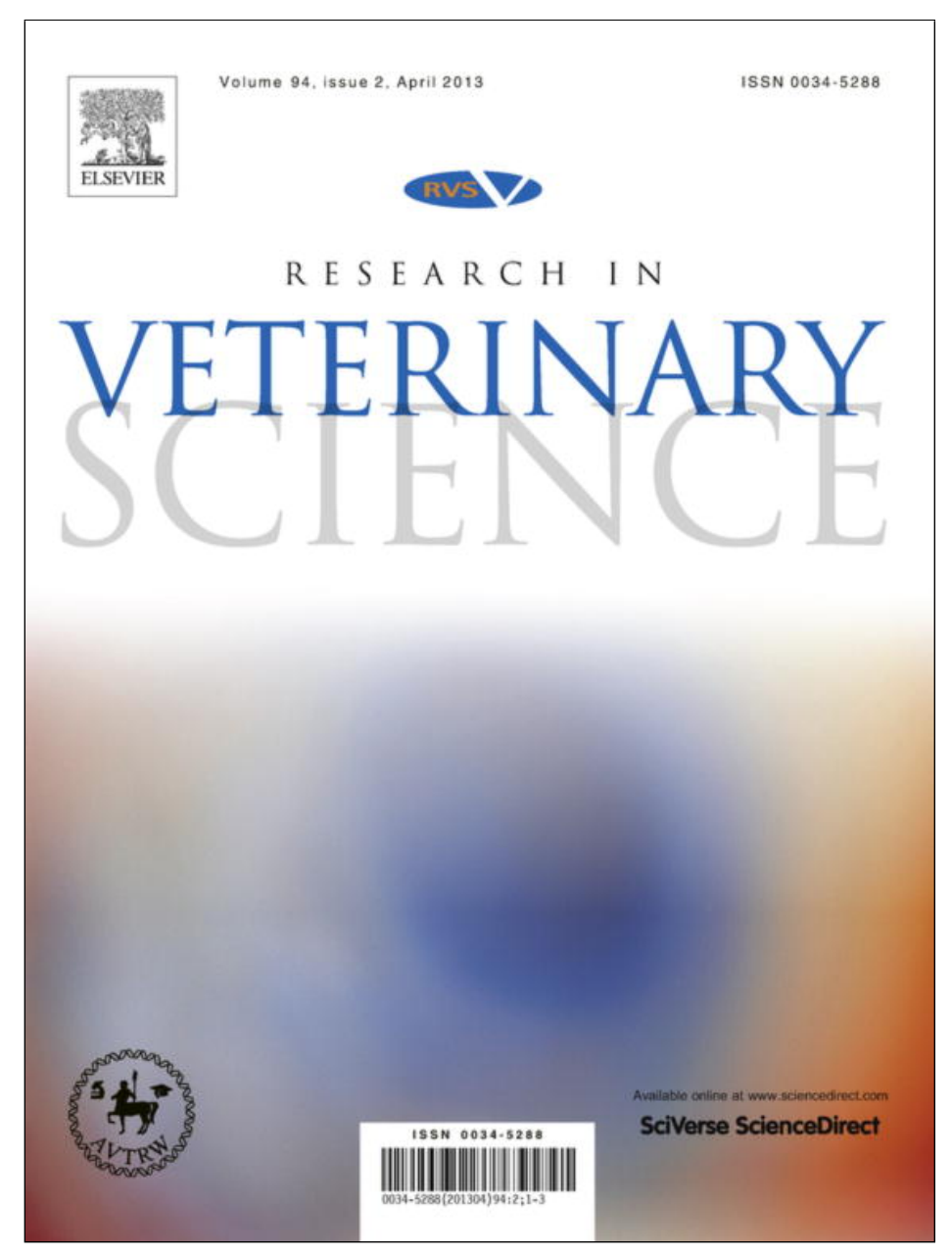

This article appeared in a journal published by Elsevier. The attached copy is furnished to the author for internal non-commercial research and education use, including for instruction at the authors institution and sharing with colleagues.

Other uses, including reproduction and distribution, or selling or licensing copies, or posting to personal, institutional or third party websites are prohibited.

In most cases authors are permitted to post their version of the article (e.g. in Word or Tex form) to their personal website or institutional repository. Authors requiring further information regarding Elsevier's archiving and manuscript policies are encouraged to visit:

http://www.elsevier.com/copyright 


\title{
Effects of EPA and DHA on lipid droplet accumulation and mRNA abundance of PAT proteins in caprine monocytes
}

\author{
Cristina Lecchi ${ }^{\mathrm{a}, \mathrm{d}}$, Guido Invernizzi ${ }^{\mathrm{b}}$, Alessandro Agazzi ${ }^{\mathrm{b}, \mathrm{d}}$, Silvia Modina ${ }^{\mathrm{c}, \mathrm{d}}$, Paola Sartorelli ${ }^{\mathrm{a}, \mathrm{d}}$, \\ Giovanni Savoini ${ }^{\text {b,d, }}$, Fabrizio Ceciliani ${ }^{\text {a,d,* }}$ \\ a Dipartimento di Patologia Animale, Igiene e Sanità Pubblica Veterinaria. Università di Milano, via Celoria 10, 20133 Milano, Italy \\ ${ }^{\mathrm{b}}$ Dipartimento di Scienze e Tecnologie Veterinarie per la Sicurezza Alimentare. Università di Milano, via Celoria 10, 20133 Milano, Italy \\ ${ }^{\mathrm{c}}$ Dipartimento di Scienze Animali. Università di Milano, via Celoria 10, 20133 Milano, Italy \\ d CISMA Centro Interdipartimentale di Studi sulla Ghiandola Mammaria, Università di Milano, via Celoria 10, 20133 Milano, Italy
}

\section{A R T I C L E I N F O}

\section{Article history:}

Received 10 February 2012

Accepted 26 September 2012

\section{Keywords:}

Monocyte

PUFA

Goat

Lipid droplets

PAT family

\begin{abstract}
A B S T R A C T
The present study investigated the in vitro effects on caprine monocytes of two $\omega-3$ PUFAs, namely eicosapentaenoic acid (EPA) and docosahexaenoic acid (DHA) on lipid droplet formation, an emerging process of fundamental importance in innate immunity regulation. The mRNA abundance of PAT protein family (PLIN1, PLIN2 and PLIN3), involved in the formation and trafficking of the droplets, was also assessed. The effects of EPA and DHA on monocyte apoptosis were studied as well. The number of lipid droplets per cell was found to be dependent on both type and concentration of fatty acid. $\omega-3$ PUFAs upregulated PLIN3 and PLIN2 gene expression, as well as apoptosis rate. The present findings suggest that PUFA might modify innate immune functions of goat monocytes by interfering with the formation of lipid droplets and by upregulating proteins belonging to PAT protein family.

(c) 2012 Elsevier Ltd. All rights reserved.
\end{abstract}

\section{Introduction}

Polyunsaturated fatty acids (PUFAs) metabolism, in particular that of $\omega-3$ PUFAs, is of fundamental importance in regulating immune-cell function (Calder, 2001). The most powerful immunomodulatory effect is achieved by two $\omega-3$ PUFAs, namely

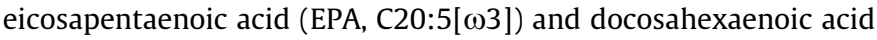

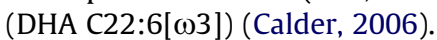

Long chain $\omega-3$ PUFAs modulate immune functions in several ways. They alter the levels of phospholipid-derived second messengers (Madani et al., 2001) and the composition of lipid-raft associated proteins (Fan et al., 2003), modulating the production of inflammatory eicosanoids (Lee et al., 1985) and interfering directly with cytokine gene expression (Yaqoob and Calder, 1995). Finally, both EPA and DHA give rise to a newly discovered family of anti-inflammatory mediators called resolvins (Serhan et al., 2002). Most of these activities directly target monocyte/macrophage defensive functions by modulating phagocytosis (Halvorsen et al., 1997), chemotaxis (Schmidt et al., 1992) and proinflammatory cytokine expression (Babcock et al., 2002). While still not completely understood, the main biological effect of $\omega 3$

* Corresponding author at: Dipartimento di Patologia Animale, Igiene e Sanità Pubblica Veterinaria. Università di Milano, via Celoria 10, 20133 Milano, Italy. Tel.: +3902 50318100; fax: +390250318095.

E-mail address: fabrizio.ceciliani@unimi.it (F. Ceciliani). long chains fatty acids has been ascribed to their incorporation in cell membrane phospholipids, thus affecting eicosanoid synthesis and altering membrane fluidity (Das, 2006). Since $\omega-3$ PUFA are also stored in lipid droplets, a mechanism of action to explain their modulatory activity on immune cells involving lipid droplet formation has been hypothesized in the past (Finstad et al., 1998). Lipid droplets, also named lipid bodies or adiposomes, are lipid-rich organelles, their cytoplasmic accumulation representing a common feature of innate immunity reactions and inflammatory conditions (Pacheco et al., 2002). The molecular mechanisms regulating the formation and metabolism of lipid droplets are not well understood. Structurally, lipid droplet consist of a lipid core surrounded by a phospholipid monolayer, which contains various proteins involved in lipid metabolic processes such as lipolysis or lipogenesis (Bozza et al., 2009). The major structural proteins present at the surface of lipid droplet are those belonging to the proteins of the PAT family, named after perilipin (PLIN1), adipophilin (PLIN2), and tail-interacting protein of $47 \mathrm{kDa}$ (TIP47), or perilipins (Kimmel et al., 2010). These proteins have been implicated in the lipid droplet assembling and biogenesis (Bickel et al., 2009). Different from neutral lipid storing cells, monocytes have virtually no lipid droplet under resting conditions. However, increased numbers of cytoplasmic lipid droplet in monocytes are often associated with infectious and other inflammatory conditions (Das, 2006). 
While $\omega-3$ fatty acids are long since utilized as lipid sources in goat diets with the aim to increase the proportion of nutritionally beneficial $\omega$-3 PUFAs in milk for human consumption (Cattaneo et al., 2006), yet few studies have been carried out to investigate the effects of fish oil-derived PUFAs on leukocyte function in this species. The information available clearly evidenced an effect on leukocyte functions both in vivo (Agazzi et al., 2004; Thanasak et al., 2004; Bronzo et al., 2010) and in vitro on isolated neutrophils (Pisani et al., 2009) and monocytes (Lecchi et al., 2011).

The aim of this study was to investigate the relationship between EPA and DHA treatment and the formation of lipid droplets, in goat monocytes. The mRNA abundance of the three major perilipins, namely PLIN1, PLIN2 and PLIN 3, which are involved in lipid droplet formation, was also investigated by quantitative PCR. Finally, since both perilipins and $\omega-3$ PUFA are involved in the regulation of cell lifespan, apoptosis rate of caprine monocytes after EPA and DHA treatment was also assessed by caspases $3 / 7$ activity measurement.

\section{Materials and methods}

\subsection{Materials}

HEPES (4-(2-hydroxyethyl)-1-piperazineethanesulfonic acid), EDTA (ethylenediaminetetraacetic acid), RPMI-1640, Red Blood Cell Lysing Buffer Hybri-Max, DHA (cis-4, 7, 10, 13, 16, 19Docosahexaenoic acid sodium salt), EPA (cis-5, 8, 11, 14, 17Eicosapentaenoic acid sodium salt), Nile Red, PBS without $\mathrm{Ca}^{++}$ and $\mathrm{Mg}^{++}$and endotoxin-free water were purchased from Sigma-Aldrich Co. (Milano, Italy). Fetal Bovine Serum (FBS) was provided by Biochrom AG (Berlin, Germany) and Ficoll 1077 by GE Healthcare Europe GmbH (Munich, Germany).

MACS Separation Columns and CD14 Microbeads were purchased from Miltenyi-Biotech (Calderara di Reno, Bologna, Italy), the RNeasy Mini Kit from Qiagen GmbH (Milano, Italy), iSCRIPT cDNA SYNTESIS Kit and SYBR Green mix from BIORAD Laboratories (Segrate, Milano, Italy) and Apo-ONE ${ }^{\circledR}$ Homogeneous Caspase-3/7 Assay was obtained from Promega Corporation (Milano, Italy). $\mathrm{MgCl}_{2}$, dNTPs and Taq polymerase were purchase from Vivantis Inc. (Oceanside, Ca, USA).

Six wells sterile cell culture plates and 384 wells black sterile cell culture plates were purchased from Nunc (Rochester, NY, USA).

\subsection{Preparation of PUFAs}

Stock solution of DHA sodium salt and EPA sodium salt were prepared as previously described (Zhao et al., 2005). The DHA and EPA sodium salts were reconstituted in endotoxin-free water at the concentration of $14.3 \mathrm{mM}$ and $15.4 \mathrm{mM}$, respectively and were stored in the dark at $-80^{\circ} \mathrm{C}$ to prevent peroxidation for no longer than 6 months. The doses of PUFAs used ranged from 0 to $200 \mu \mathrm{M}$ (Thanasak et al., 2005).

\subsection{Source and purification of caprine monocytes}

Six clinically healthy multiparous lactating goats (Saanen) between 5 and 6 years of age and between 30 and 33 weeks after parturition were used for blood collection. Goat diet was based on alfalfa hay and a commercial concentrate mix without any $\omega-3$ fatty acids supplement added. Blood samples were collected before feeding administration by venipuncture from the jugular vein into $10 \mathrm{ml}$ K3 EDTA vacuum sterile glass tubes. Samples were delivered to laboratory within $2 \mathrm{~h}$ at $5^{\circ} \mathrm{C}$.

Blood was centrifuged at $1260 \mathrm{~g}$ for $30 \mathrm{~min}$ at room temperature in order to obtain the buffy coat. Mononuclear cells were obtained after dilution of the buffy coat $1: 5(\mathrm{vol} / \mathrm{vol})$ in cold PBS with $2 \mathrm{mM}$ EDTA and $10 \mathrm{ml}$ of this solution were overlaid on $3 \mathrm{ml}$ Ficoll 1077 and centrifuged for $30 \mathrm{~min}$ at $1500 \mathrm{~g}$ at $4{ }^{\circ} \mathrm{C}$. Mononuclear cells were collected from the interface. The cells were resuspended in $50 \mathrm{ml}$ cold PBS with $2 \mathrm{mM}$ EDTA and centrifuged for $7 \mathrm{~min}$ at $400 \mathrm{~g}$ at $4{ }^{\circ} \mathrm{C}$ in order to remove platelets. This step was repeated four times. The remaining erythrocytes were lysed with Red Blood Cell Lysing Buffer Hybri-Max.

Monocyte $\left(\mathrm{CD} 14^{+}\right)$cells isolation was carried out using magnetic activated cellular sorting. Briefly, Peripheral Blood Mononuclear Cell (PBMC) were incubated with anti-human CD14 labeled super-paramagnetic beads $\left(20 \mu \mathrm{l} / 10^{8}\right.$ cells) for $15 \mathrm{~min}$ at $4{ }^{\circ} \mathrm{C}$ and CD14 ${ }^{+}$cells were isolated from a MidiMacs column according to the manufacturer's instruction. The purity of the sorted cells $(>95 \%)$ was evaluated by flow cytometry. Cell viability, as determined by Trypan Blue exclusion, was $>95 \%$.

\subsection{Caprine monocyte apoptosis measurement}

The concentration of monocytes was adjusted to $2 \times 10^{6} / \mathrm{ml}$ and $25 \mathrm{\omega l}$ of this solution ( $5 \times 10^{4}$ cells) were seeded in 384 wells black sterile cell culture plates and incubated for $24 \mathrm{~h}$ at $37^{\circ} \mathrm{C}$ in humidified atmosphere of $5 \% \mathrm{CO}_{2}$. The DHA and EPA were diluted in medium (RPMI 1640 with $20 \mathrm{mM}$ HEPES, 10\% heat inactivated FBS, $100 \mu \mathrm{U}$ penicillin $/ \mathrm{ml}, 100 \mu \mathrm{g}$ streptomycin $/ \mathrm{ml}$ ) to concentration of $0,25,50,100$ and $200 \mu \mathrm{M}$. All the experiments were carried out in triplicate.

Apoptosis was determined by measuring the modification of the activities of two enzymes that play effector roles in apoptosis: caspase- 3 and caspase-7 as previously described in bovine (Ceciliani et al., 2007).

\subsection{Measurement of intracellular lipid droplets}

Caprine monocytes were seeded in number of $1.5 \times 10^{5}$ in 6 wells sterile cell culture plates containing sterile coverslips and were incubated for $24 \mathrm{~h}$ at $37^{\circ} \mathrm{C}$ in humidified atmosphere of $5 \%$ $\mathrm{CO} 2$ in air. The DHA and EPA were diluted in complete RPMI (RPMI 1640 with $20 \mathrm{mM}$ HEPES, $10 \%$ heat inactivated FBS, $100 \mu \mathrm{U}$ penicil$\mathrm{lin} / \mathrm{ml}, 100 \mu \mathrm{g}$ streptomycin $/ \mathrm{ml}$ ) to final concentration of $0,25,50$, 100 and $200 \mu \mathrm{M}$. The coverslips were collected from the cell culture plates and washed twice in cold PBS; the cells were then fixed with $2 \%$ formalin at room temperature for $30 \mathrm{~min}$ and stained with $0.15 \mu \mathrm{g} / \mathrm{ml}$ Nile Red for $15 \mathrm{~min}$. Nile Red was prepared as described by Listenberger and Brown (2007). After the first staining with Nile Red, the cover slips were washed twice in PBS and chromatin DNA was stained with DAPI $(0.05 \mu \mathrm{g} / \mathrm{ml}$ in PBS). Nile Red fluorescence intensity was stable for several hours. All samples were mounted with an anti-fade medium (Vectashield Vector lab., Burlingame, CA, USA) and observed with a conventional epifluorescence microscope (Eclipse E 600, Nikon, Torino, Italy) at a $100 \times$ magnification. Quantification of lipid droplet number and size was carried out using ImageJ software (NIH, Bethesda, MA, USA) (Stringer et al., 2010). Ten fields were randomly selected and the cells were divided in negative cells, in which no fluorescence was detected, and positive cells with lipid droplets. For quantification of the number measurements, all lipid droplets within the ten fields were counted.

\subsection{Perilipin mRNA abundance assessment}

The concentration of caprine monocytes was adjusted to $3 \times 10^{6} / \mathrm{ml}$ and $1 \mathrm{ml}$ of this solution was seeded in 6 wells sterile cell culture plates and incubated for $24 \mathrm{~h}$ at $37{ }^{\circ} \mathrm{C}$ in humidified atmosphere of $5 \% \mathrm{CO}_{2}$ in air. The DHA and EPA were diluted in complete RPMI (RPMI 1640 with $20 \mathrm{mM}$ HEPES, 10\% heat 
inactivated FBS, $100 \mu \mathrm{U}$ penicillin/ml, $100 \mu \mathrm{g}$ streptomycin $/ \mathrm{ml}$ ) to final concentration of $0,25,50,100$ and $200 \mu \mathrm{M}$. Total RNA was extracted from stimulated monocytes using the RNeasy Mini Kit according to the manufacturer's protocol. The reverse transcription (RT) reaction was carried out on $1 \mu \mathrm{g}$ RNA using an iScript ${ }^{\mathrm{TM}} \mathrm{cDNA}$ Synthesis Kit. The thermal profile was according to the manifacturer's recommendations.

To perform gene testing, the cDNA derived was pooled and used as the template for PCR reactions; cDNA purified from caprine perirenal adipose tissue was used as positive control. The reactions were carried out in a $10 \mu \mathrm{L}$ final volume containing $1 \times$ buffer, $1.5 \mathrm{mM} \mathrm{MgCl}_{2}, 0.2 \mathrm{mM}$ each deoxynucleotide triphosphates (dNTPs), $1 \mu \mathrm{M}$ each primer and $0.025 \mathrm{U}$ Taq polymerase. The same primers were used in qualitative and quantitative PCR (Table 1). Amplifications were performed using 35 cycles of $94{ }^{\circ} \mathrm{C}$ for $30 \mathrm{~s}$ (denaturation), $60{ }^{\circ} \mathrm{C}$ for $30 \mathrm{~s}$ (annealing) and $72^{\circ} \mathrm{C}$ for $45 \mathrm{~s}$ (extension) (Eppendorf Mastercycler). PCR products were visualized on $1.9 \%$ agarose gels stained with ethidium bromide.

Quantitative reactions were performed in $25 \mu \mathrm{L}$ of SYBR ${ }^{\circledR}$ Green mix and: $400 \mathrm{nM}$ of SDHA primers and PLIN3 primers and $300 \mathrm{nM}$ of YWHAZ primers and PLIN2 primers. In order to evaluate the PCR efficiency using a relative standard curve, series of dilution were prepared by performing 4 -fold serial dilution starting from pooled cDNA sample in triplicate, obtained by mixing $2 \mu \mathrm{l}$ of each sample. Each sample was tested in duplicate. The thermal profile used (95 ${ }^{\circ} \mathrm{C}$ for $90 \mathrm{~s}, 50$ cycles of $95^{\circ} \mathrm{C}$ for $15 \mathrm{~s}$ and $62{ }^{\circ} \mathrm{C}$ for $60 \mathrm{~s}$; for melting curve construction, $55^{\circ} \mathrm{C}$ for $60 \mathrm{~s}$ and 80 cycles starting to $55^{\circ} \mathrm{C}$ and increasing $0.5{ }^{\circ} \mathrm{C}$ each $10 \mathrm{~s}$ ) was the same for each target gene. The results obtained were compared using the delta-delta Cq method (Giulietti et al., 2001) after normalization of the sample using the SDHA and YWHAZ as reference genes, which were selected as housekeeping gene following previous studies on bovine White Blood Cells (De Ketelaere et al., 2006; Spalenza et al., 2011) and other tissues (Goossens et al., 2005; Lisowski et al., 2008; Bougarn et al., 2011).

\subsection{Statistical analysis}

Apoptosis data were analyzed by ANOVA using the General Linear Model of SAS (SAS/STAT, Version V8, 1999, SAS Inst., Inc., NC, USA). Significance was declared for $P<0.01$ and $P<0.05$.

\section{Results}

\subsection{EPA and DHA modulate caprine monocyte apoptosis only when} used at high concentrations

To investigate the apoptosis-modulating activity of EPA and DHA, the enzymatic activities of caspase- 3 and caspase-7, the two major executioners of the apoptosis pathway, were measured. Caspase-3/7 activity was detected $24 \mathrm{~h}$ after monocytes medium supplementation with EPA or DHA. The results showed that treatment with low doses (between 25 and $100 \mu \mathrm{M}$ ) of both fatty acids did not influence the apoptosis rate compared with untreated cells. On the contrary, higher concentrations of both fatty acids $(200 \mu \mathrm{M})$ induced a significantly increase of monocytes apoptosis: in particular, EPA caused an increase of 35\% $(P<0.01)$ compared with untreated cells (Fig. 1A), while DHA an increase of $24.9 \%$ $(P<0.05)$ (Fig. 1B).

\subsection{Intracellular lipid accumulation was differentially modulated by EPA and DHA}

In order to determine whether treatment with EPA and DHA was associated with intracellular accumulation of neutral lipids, monocytes were grown on slides and incubated for $24 \mathrm{~h}$ with EPA and DHA at $50 \mu \mathrm{M}$ or $200 \mu \mathrm{M}$. The experimental concentration of EPA and DHA was selected based on apoptosis experiments that showed marginal differences between $25 \mu \mathrm{M}$ and $100 \mu \mathrm{M}$, the higher effect being observed at a concentration of $200 \mu \mathrm{M}$. The results obtained are showed in Fig. 2. Panel A presents isolated monocytes after Nile Red (lipid droplets) and DAPI (nucleus) staining. The number of lipid droplets per cell was dependent on both type and concentration of fatty acid. Treatment of caprine monocytes with EPA and DHA resulted in intracellular accumulation of lipid droplets. In particular, treatment of monocytes with EPA, even when added at a low concentration $(50 \mu \mathrm{M})$ induced an accumulation of lipid droplets in $18 \%$ of goat monocytes (Fig 2B). On the contrary, DHA had fewer effects ( $94 \%$ negative cells where no droplets are observed).

When cells were treated with high concentration of fatty acids, the number of intracellular lipid droplets was dramatically modified. When added at $200 \mu \mathrm{M}$, DHA was more effective than EPA in increasing the accumulation of lipid droplets. In particular, the number of droplets was 10 -fold increased, stepping from $6 \%$ to $63 \%$. The effects of EPA were less evident. Treating monocytes with high concentrations of EPA resulted in an increase of droplets from $20 \%$ to $40 \%$.

\subsection{PLIN2 and PLIN3 $m R N A$ abundance was regulated by EPA and DHA}

The effects of EPA and DHA on three proteins belonging to the perilipin family, namely PLIN1, PLIN2 and PLIN3, were investigated by incubating caprine monocytes for $24 \mathrm{~h}$ with or without fatty acids and mRNA abundance was determined by quantitative PCR.

In order to investigate the presence of perilipin in goat, mRNA from $\mathrm{CD} 14^{+}$monocytes was examined by qualitative PCR. PLIN2 and PLIN3 specific bands were detected in CDNA of monocytes stimulated with EPA and DHA and positive control (adipose tissue). Monocytes did not produce detectable amount of PLIN1 mRNA, as shown in Fig. 1 supplemental.

The relative quantification of PLIN2 and PLIN3 mRNA was carried by delta-delta Cq method after normalization of the sample using the SDHA and YWHAZ as reference genes. Results are presented in Fig. 3.

Table 1

Sequences of oligonucleotide primers for perilipin.

\begin{tabular}{|c|c|c|c|}
\hline Symbol & Alias & Sense & Antisense \\
\hline PLIN1 & Perilipin & 5'-GTCGAGAAGATGGTAGAGTTCCTC-3' & 5'-TGGAAGGTGTGTCTAGAGAGAGTG-3' \\
\hline PLIN2 & Adipocyte differentiation-related protein (ADPR) & 5'-CTGCTGGCTGATTTCTTCTTTCTC-3' & 5'-TGATGTAAGCCGAGGAGACCA-3' \\
\hline PLIN3 & Tail-interacting protein of 47 kDa (PLIN3) & 5'-GAGCATCACATCCGTCATTAGG-3' & 5'-AGGGTGTGGGATGTAAGAAC-3' \\
\hline SDHA & Succinate dehydrogenase complex, subunit A & 5'-TGTATAATAGCTCACGCCCG-3' & 5'-TCTATCAGATGGCCTCCTCAG-3' \\
\hline YWHAZ & $\begin{array}{l}\text { Tyrosine } 3 \text {-monooxygenase/tryptophan 5-monooxygenase } \\
\text { activation protein, zeta polypeptide }\end{array}$ & 5'-GCATCCCACAGACTATTTCC-3' & 5'-GCAAAGACAATGACAGACCA-3' \\
\hline
\end{tabular}

The PLIN2, PLIN3 and SDHA were designed on the basis of GenBank sequences (accession numbers AF541976, NM001077046.1 and NM174178.2 respectively). The PLIN1 primers sequences were from Xu et al. (2011) and the YWHAZ primers from Goossens et al. (2005). 

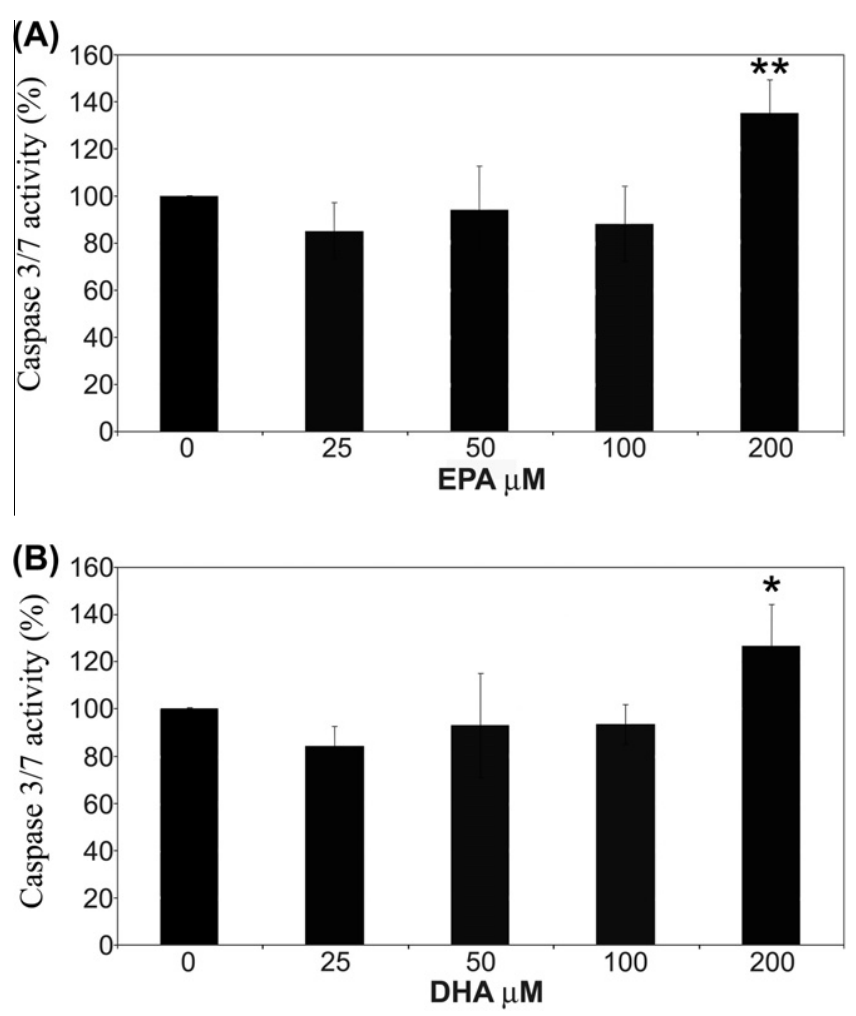

Fig. 1. Effect of EPA and DHA on caprine monocyte apoptosis rate. Positively selected blood monocytes were cultured for $24 \mathrm{~h}$ with different concentration of EPA (panel A) or DHA (panel B). Apoptosis was determined by measuring the modification of the caspase-3/7 enzymatic activities. Each assay was carried out in triplicate. The data are expressed as percentage of enzymatic activity and are means \pm SEM of six independent experiments compared with control (100\%). Asterisks indicate statistically significant difference from control $\left({ }^{*} P<0.05\right.$; $\left.{ }^{* *} P<0.01\right)$.

EPA and DHA differentially modulated the PLIN2 and PLIN3 mRNA expression. EPA at $200 \mu \mathrm{M}$ significantly $(P<0.05)$ upregulated PLIN3 mRNA expression, when compared with lower fatty acid concentration. On the contrary, DHA at $200 \mu \mathrm{M}$ upregulated $(P<0.05)$ PLIN2 mRNA expression, when compared with lower concentrations, while PLIN3 abundance remained unchanged.

\section{Discussion}

The present study explored the possible relationship between EPA and DHA, two $\omega-3$ PUFA commonly utilized as lipid diet integrators, and in vitro lipid droplet formation in caprine monocytes. The number of lipid droplets per cell was found to be dependent on both type and concentration of fatty acid. There is growing evidence that lipid droplets are not simply storage depots of neutral lipids, but play a precise, yet still partially undisclosed, role as inflammatory organelles (Bozza et al., 2009), probably behaving as intracellular site for eicosanoid generation during inflammation and storage of other important signaling molecules (Bozza et al., 2007).

Both EPA and DHA modulate immune activities of goat granulocytes and monocytes, including phagocytosis and oxidative burst (Pisani et al., 2009; Lecchi et al., 2011). In general, the immunomodulatory effect on leukocytes is attributed to the incorporation of dietary PUFA in phospholipids of leukocyte cellular membranes, where they are supposed to affect cellular eicosanoid synthesis and lipid peroxidation, thus altering the fluidity of cell membranes (Calder, 2006).
The relationship between EPA and DHA co-incubation and the formation of lipid droplets suggests a new possible innate immunity regulatory function of PUFA, at least in this species.

The major structural proteins that can be found at the surface of lipid droplets are those belonging to the PAT family, also known as perilipins (Bozza et al., 2009).

Since these proteins are also involved in lipid body biogenesis and assembly (Bickel et al., 2009), we hypothesized that EPA and DHA may influence the fusion process of lipid droplets by regulating perilipin mRNA expression. The second part of the study was therefore focused on the assessment of mRNA abundance of three proteins belonging to PAT family, namely PLIN1, PLIN2 and PLIN3, in order to ascertain whether EPA and DHA may influence their synthesis.

Goat monocytes did not produce detectable amounts of PLIN1 mRNA. On the contrary, both EPA and DHA upregulated mRNA expression of PLIN2 and PLIN3 when cells were treated with high concentrations of $\omega-3$ PUFA. The function of PLIN2 is to stimulate lipid accumulation, lipid-droplet formation and lipolysis (Fukushima et al., 2005), whereas PLIN3 participates in nascent lipid droplet formation, when cellular lipid influx increases (Wolins et al., 2006). Since the modulation of PLIN2 and PLIN3 in caprine monocytes is associated with the increasing availability of $\omega-3$ PUFAs, it can be hypothesized that EPA and DHA may modulate lipid droplet formation by regulating PLIN2 and PLIN3 mRNA expression. This activity can have a profound impact on monocyte immune functions, since a relationship between perilipin expression and innate immunity reactions has been recently demonstrated. For example, PLIN2 expression is increased during innate immunity response against leprosy (Mattos et al., 2011), and regulates MCP1 production by human monocytes (Wurfel et al., 2005). PLIN2 was also found to be involved in dendritic cell antigen presentation (Bougnères et al., 2009).

At the highest EPA and DHA concentration $(200 \omega \mathrm{M})$, the formation of lipid droplets was accompanied by the initiation of apoptosis. No pro-apoptotic effects were detected at $\omega-3$ PUFA concentrations of $100 \omega \mathrm{M}$. Therefore, neither EPA nor DHA substantially alter the lifespan of goat monocytes when utilized at doses that have been found to exert an immunomodulatory activity (Pisani et al., 2009; Lecchi et al., 2011). Polyunsaturated fatty acids' concentration utilized in the present investigation ranged from 50 to $200 \mu \mathrm{M}$ and was consistent with physiological concentration of EPA and DHA in goat serum (180 and $115 \mu \mathrm{M}$, respectively) (Yeom et al., 2005).

This information may be useful in formulating goat diets, where $\omega-3$ PUFA are commonly utilized as lipid source to ameliorate the percentage of unsaturated fatty acids in meat and dairy products (Moghadasian, 2008). Even when not protected, dietary administered $\omega$-3 PUFAs are hydrogenated only to a small extent by rumen microorganisms (Ashes et al., 1992; Gulati et al., 1999). Therefore, EPA and DHA can be found in both blood and milk (Cattaneo et al., 2006), where they may contribute to modulate immune defences (Thanasak et al., 2004; Agazzi et al., 2004).

The capability of dietary $\omega$-3-PUFA to skip the ruminal hydrogenation represents a double edge sword. On one hand it allows the delivery through diet of these important, and mostly beneficial, molecules, to the organism. On the other hand, poorly balanced diets and/or excessive intake by single goats may increase their blood concentration, eventually altering the processing stability and organoleptic quality of milk. In the present finding we provided the evidence that high concentrations of EPA and DHA promote monocyte apoptosis, which in turn might downregulate goat immune defences.

Therefore, the potential toxicity of high concentrations of $\omega-3$ PUFA that have been shown in this study should be taken into account in formulating diet including these highly biologically active molecules. 

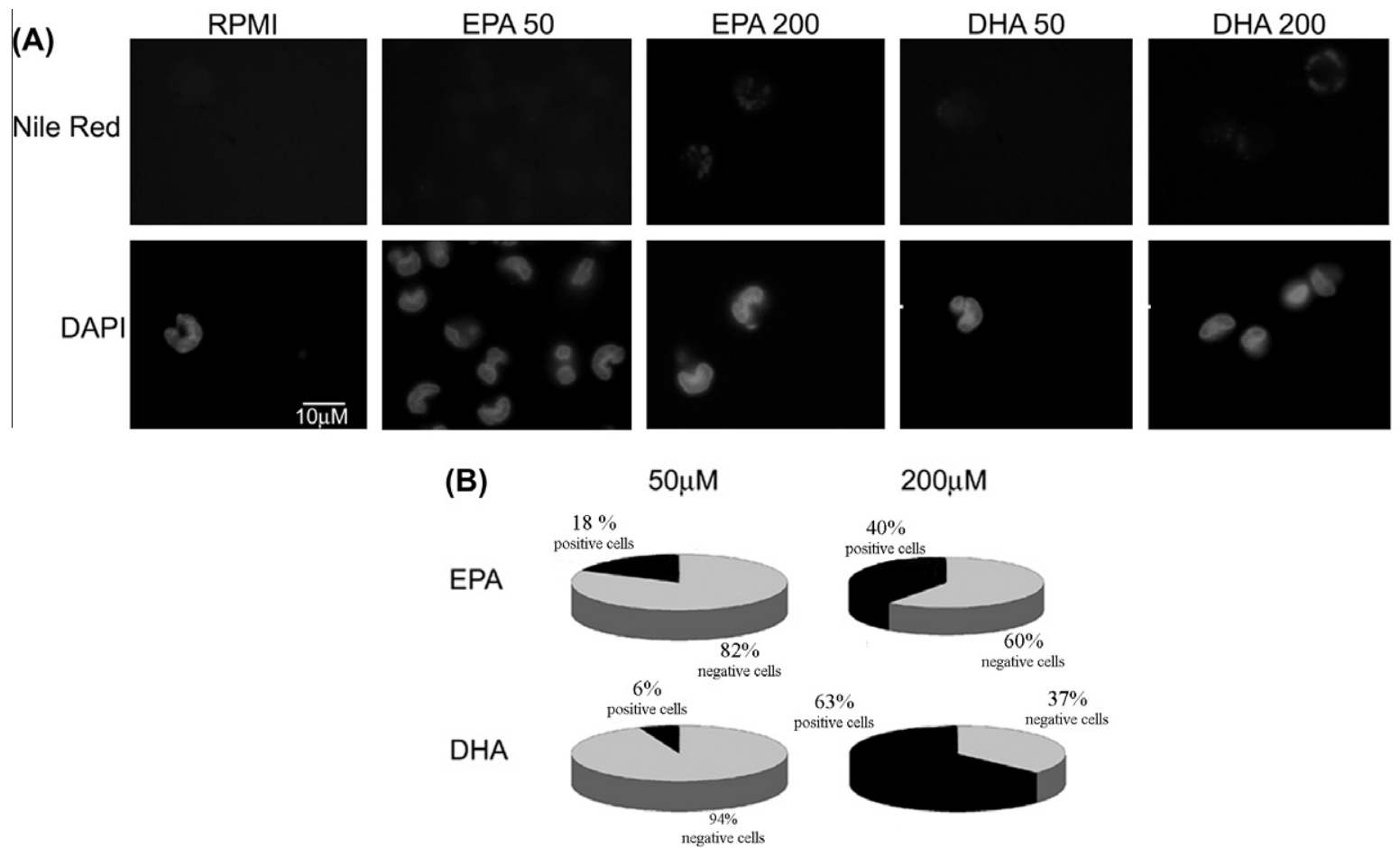

Fig. 2. Effects of EPA and DHA treatment on lipid droplet formation. Lipid droplets content in caprine monocytes incubated without fatty acids or with EPA or DHA. Isolated monocytes were cultured for $24 \mathrm{~h}$ in presence of $50 \mu \mathrm{M}$ and $200 \mu \mathrm{M}$ EPA or DHA and stained with Nile Red and DAPI nuclear staining (A). One representative set of photographs from three separate experiments is shown. RPMI cultured cells were $100 \%$ negative. Magnification: $100 \times$. (B) Ten fields were counted and monocytes were divided in negative and positive cells.
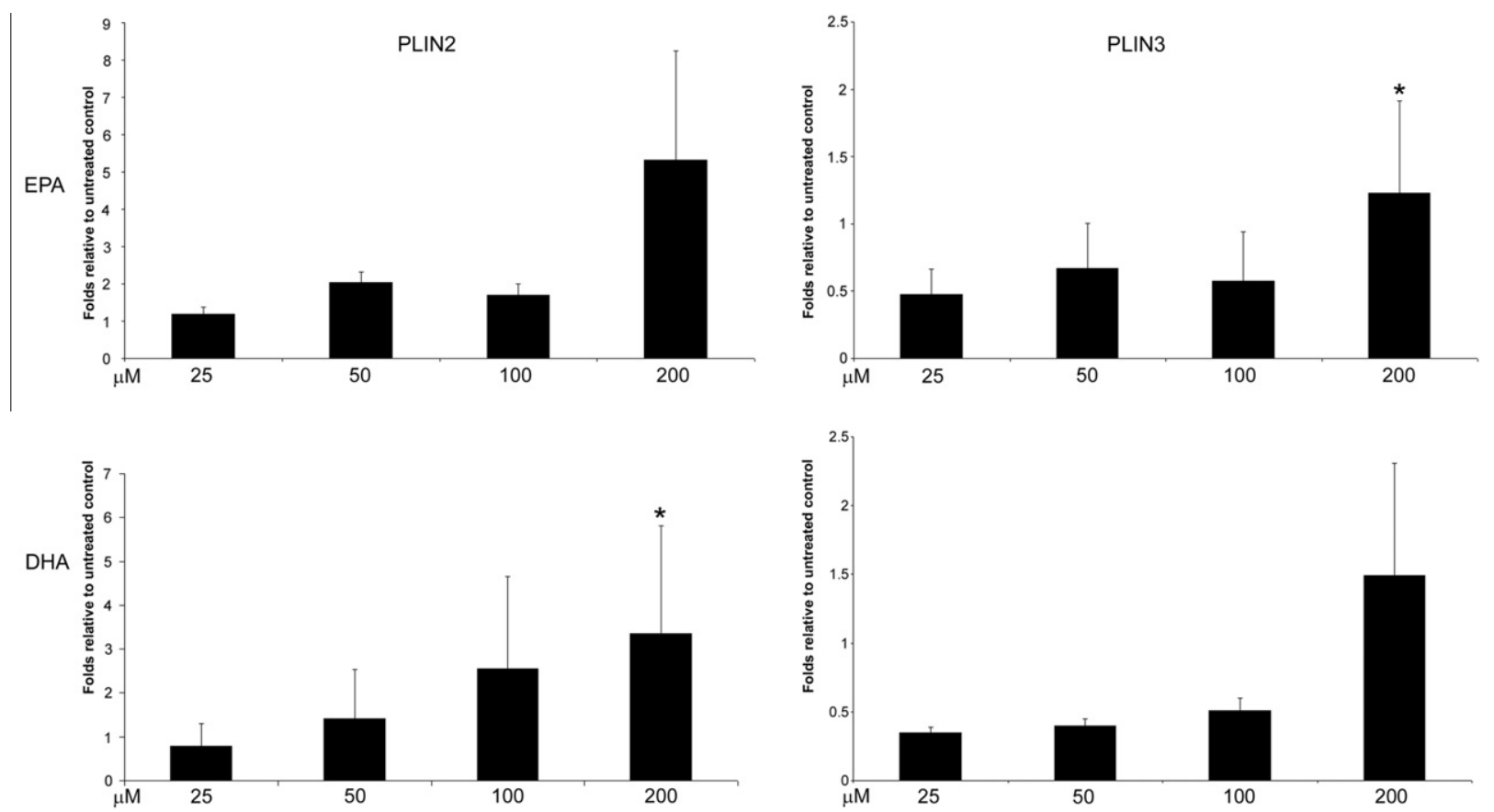

Fig. 3. Effects of EPA and DHA on PLIN2 and PLIN3 mRNA abundance. Relative PLIN2 and PLIN3 mRNA abundance in monocytes incubated with EPA (A and B) or DHA (C and D) for $24 \mathrm{~h}$. The results were normalized using SDHA and YWHAZ as housekeeping genes. mRNA levels of PLIN2 and PLIN3 are expressed relative to untreated cells. Data are expressed as fold \pm SEM calculated from three independent experiments. Asterisks indicate significant difference from control $\left({ }^{*} P<0.05\right.$ ).

\section{Acknowledgements}

Hereby we acknowledge Mattia Crivelli, the owner of the goats farm "Il Vallone" (Cittiglio, Varese, Italy) for his willingness to help and kindness.

\section{Appendix A. Supplementary data}

Supplementary data associated with this article can be found, in the online version, at http://dx.doi.org/10.1016/j.rvsc.2012.09. 019. 


\section{References}

Agazzi, A., Cattaneo, D., Dell'Orto, V., Moroni, P., Bonizzi, L., Pasotto, D., Bronzo, V., Savoini, G., 2004. Effect of administration of fish oil on aspects of cell-mediated immune response in periparturient dairy goats. Small Ruminant Research 55, 77-83.

Ashes, J.R., Siebert, B.D., Gulati, S.K., Cuthbertson, A.Z., Scott, T.W., 1992. Incorporation of n-3 fatty acids of fish oil into tissue and serum lipids of ruminants. Lipids 27 (8), 629-631.

Babcock, T.A., Helton, W.S., Hong, D., Espat, N.J., 2002. Omega-3 fatty acid lipid emulsion reduces LPS-stimulated macrophage TNF-alpha production. Surgical Infections (Larchmt) 3, 145-149.

Bickel, P.E., Tansey, J.T., Welte, M.A., 2009. PAT proteins, an ancient family of lipid droplet proteins that regulate cellular lipid stores. Biochimica et Biophysica Acta 1791 (6), 419-440.

Bougarn, S., Cunha, P., Gilbert, F.B., Meurens, F., Rainard, P., 2011. Technical note: Validation of candidate reference genes for normalization of quantitative PCR in bovine mammary epithelial cells responding to inflammatory stimuli. Journal of Dairy Science 94 (5), 2425-2430.

Bougnères, L., Helft, J., Tiwari, S., Vargas, P., Chang, B.H., Chan, L., Campisi, L., Lauvau, G., Hugues, S., Kumar, P., Kamphorst, A.O., Dumenil, A.M., Nussenzweig, M., MacMicking, J.D., Amigorena, S., Guermonprez, P., 2009. A role for lipid bodies in the cross-presentation of phagocytosed antigens by MHC class I in dendritic cells. Immunity 31 (2), 232-244.

Bozza, P.T., Melo, R.C., Bandeira-Melo, C., 2007. Leukocyte lipid bodies regulation and function: contribution to allergy and host defense. Pharmacology \& Therapeutics $113,30-49$.

Bozza, P.T., Magalhães, K.G., Weller, P.F., 2009. Leukocyte lipid bodies - Biogenesis and functions in inflammation. Biochimica et Biophysica Acta 1791, 540-551.

Bronzo, V., Puricelli, M., Agazzi, A., Invernizzi, G., Ferroni, M., Moroni, P., Savoini, G., 2010. Effects of protected fish oil in the diet of periparturient dairy goats on phenotypic variation in blood and milk leukocytes. Animal 4 (9), 1510-1517.

Calder, P.C., 2001. Polyunsaturated fatty acids, inflammation and immunity. Lipids $36,1007-1024$

Calder, P.C., 2006. N-3 polyunsaturated fatty acids, inflammation, and inflammatory diseases. The American Journal of Clinical Nutrition 83, 1505S-1519S.

Cattaneo, D., Dell'Orto, V., Varisco, G., Agazzi, A., Savoini, G., 2006. Enrichment in n-3 fatty acids of goat's colostrum and milk by maternal fish oil supplementation. Small Ruminant Research 64, 22-29.

Ceciliani, F., Pocacqua, V., Miranda-Ribera, A., Bronzo, V., Lecchi, C., Sartorelli, P., 2007. Alpha(1)-acid glycoprotein modulates apoptosis in bovine monocytes. Veterinary Immunology and Immunopathology 116, 145-152.

Das, U.N., 2006. Essential fatty acids: Biochemistry, physiology and pathology. Biotechnology Journal 1 (4), 420-439.

De Ketelaere, A., Goossens, K., Peelman, L., Burvenich, C., 2006. Technical note: Validation of internal control genes for gene expression analysis in bovine polymorphonuclear leukocytes. Journal of Dairy Science 89 (10), 4066-4069.

Fan, Y.Y., McMurray, D.N., Ly, L.H., Chapkin, R.S., 2003. Dietary (n-3) polyunsaturated fatty acids remodel mouse T-cell lipid rafts. Journal of Nutrition 133, 1913-1920.

Finstad, H.S., Drevon, C.A., Kulseth, M.A., Synstad, A.V., Knudsen, E., Kolset, S.O., 1998. Cell proliferation, apoptosis and accumulation of lipid droplets in U937-1 cells incubated with eicosapentaenoic acid. Biochemical Journal 336, 451-459.

Fukushima, M., Enjoji, M., Kohjima, M., Sugimoto, R., Ohta, S., Kotoh, K., Kuniyoshi, M., Kobayashi, K., Imamura, M., Inoguchi, T., Nakamuta, M., Nawata, H., 2005. Adipose differentiation related protein induces lipid accumulation and lipid droplet formation in hepatic stellate cells. In Vitro Cellular \& Developmental Biology - Animal 41 (10), 321-324.

Gulati, S.K., Ashes, J.R., Scott, T.W., 1999. Hydrogenation of eicosapentaenoic and docosahexaenoic acids and their incorporation into milk fat. Animal Feed Science and Technology 79, 57-64.

Giulietti, A., Overbergh, L., Valckx, D., Decallonne, B., Bouillon, R., Mathieu, C., 2001. An overview of real-time quantitative PCR: Applications to quantify cytokine gene expression. Methods 25 (4), 386-401.

Goossens, K., Van Poucke, M., Van Soom, A., Vandesompele, J., Van Zeveren, A., Peelman, L.J., 2005. Selection of reference genes for quantitative real-time PCR in bovine preimplantation embryos. BMC Developmental Biology 5, 27.

Halvorsen, D. S., Hansen, J.B., Grimsgaard, S., Bønaa, K.H., Kierulf, P. Nordøy, A., 1997. The effect of highly purified eicosapentaenoic and docosahexaenoic acids on monocyte phagocytosis in man. Lipids 32, 935-942.

Kimmel, A.R., Brasaemle, D.L., McAndrews-Hill, M., Sztalryd, C., Londos, C., 2010. Adoption of PERILIPIN as a unifying nomenclature for the mammalian PATfamily of intracellular lipid storage droplet proteins. Journal of Lipid Research $51(3), 468-471$.
Lecchi, C., Invernizzi, G., Agazzi, A., Ferroni, M., Pisani, L.F., Savoini, G., Ceciliani, F., 2011. In vitro modulation of caprine monocyte immune functions by $\omega-3$ polyunsaturated fatty acids. The Veterinary Journal 189 (3), 353-355.

Lee, T.H., Hoover, R.L., Williams, J.D., Sperling, R.I., Ravalese, J.3rd., Spur, B.W., Robinson, D.R., Corey, E.J., Lewis, R.A., Austen, K.F., 1985. Effect of dietary enrichment with eicosapentaenoic and docosahexaenoic acids on in vitro neutrophil and monocyte leukotriene generation and neutrophil function. New England Journal of Medicine 312 (19), 1217-1224.

Lisowski, P., Pierzchała, M., Gościk, J., Pareek, C.S., Zwierzchowski, L., 2008. Evaluation of reference genes for studies of gene expression in the bovine liver, kidney, pituitary, and thyroid. Journal of Applied Genetics 49 (4), 367372 .

Listenberger, L.L., Brown, D.A., 2007. Fluorescent Detection of Lipid Droplets and Associated Proteins. Current Protocols in Cell Biology (Chapter 24, Unit 24.2).

Madani, S., Hichami, A., Legrand, A., Belleville, J., Khan, N.A., 2001. Implication of acyl chain of diacylglycerols in activation of different isoforms of protein kinase C. FASEB Journal 15, 2595-2601.

Mattos, K.A., Lara, F.A., Oliveira, V.G., Rodrigues, L.S., D’Avila, H., Melo, R.C., Manso, P.P., Sarno, E.N., Bozza, P.T., Pessolani, M.C., 2011. Modulation of lipid droplets by Mycobacterium leprae in Schwann cells: a putative mechanism for host lipid acquisition and bacterial survival in phagosomes. Cellular Microbiology 13 (2), 259-273.

Moghadasian, M.H., 2008. Advances in dietary enrichment with n-3 fatty acids. Critical Reviews in Food Science and Nutrition 48 (5), 402-410.

Pacheco, P., Bozza, F.A., Gomes, R.N., Bozza, M., Weller, P.F., Castro-Faria-Neto, H.C., Bozza, P.T., 2002. Lipopolysaccharide-induced leukocyte lipid body formation in vivo: innate immunity elicited intracellular Loci involved in eicosanoid metabolism. Journal of Immunology 169, 6498-6506.

Pisani, L.F., Lecchi, C., Invernizzi, G., Sartorelli, P., Savoini, G., Ceciliani, F., 2009. In vitro modulatory effect of omega-3 polyunsaturated fatty acid (EPA and DHA) on phagocytosis and ROS production of goat neutrophils. Veterinary Immunology and Immunopathology 131, 79-85.

Schmidt, E.B., Varming, K., Pedersen, J.O., Lervang, H.H., Grunnet, N., Jersild, C., Dyerberg, J., 1992. Long-term supplementation with n-3 fatty acids, II: Effect on neutrophil and monocyte chemotaxis. Scandinavian Journal of Clinical \& Laboratory Investigation 52, 229-236.

Serhan, C.N., Hong, S., Gronert, K., Colgan, S.P., Devchand, P.R., Mirick, G., Moussignac, R.L., 2002. Resolvins: A family of bioactive products of omega-3 fatty acid transformation circuits initiated by aspirin treatment that counter pro-inflammation signals. Journal of Experimental Medicine 196, 1025-1037.

Spalenza, V., Girolami, F., Bevilacqua, C., Riondato, F., Rasero, R., Nebbia, C., Sacchi, P., Martin, P., 2011. Identification of internal control genes for quantitative expression analysis by real-time PCR in bovine peripheral lymphocytes. The Veterinary Journal 189 (3), 278-283.

Stringer, D.M., Zahradka, P., Declercq, V.C., Ryz, N.R., Diakiw, R., Burr, L.L., Xie, X., Taylor, C.G., 2010. Modulation of lipid droplet size and lipid droplet proteins by trans-10,cis-12 conjugated linoleic acid parallels improvements in hepatic steatosis in obese, insulin-resistant rats. Biochimica et Biophysica Acta 1801 (12), 1375-1385.

Thanasak, J., Rutten, V.P., Schonewille, J.T., Hoek, A., Beynen, A.C., Noordhuizen, J.P., Müller, K.E., 2004. Effect of a dietary n-6 polyunsaturated fatty acid supplement on distinct immune functions of goats. Journal of Veterinary Medicine series APhysiology Pathology Clinical Medicines 51, 1-9.

Thanasak, J. Müller, K.E Dieleman, S.J., Hoek, A., Noordhuizen, J.P., Rutten, V.P. 2005. Effects of polyunsaturated fatty acids on the proliferation of mitogen stimulated bovine peripheral blood mononuclear cells. Veterinary Immunology and Immunopathology 104, 289-295.

Wolins, N.E., Brasaemle, D.L., Bickel, P.E., 2006. A proposed model of fat packaging by exchangeable lipid droplet proteins. FEBS Letters 580 (23), 5484-5491.

Wurfel, M.M., Park, W.Y., Radella, F., Ruzinski, J., Sandstrom, A., Strout, J., Bumgarner, R.E., Martin, T.R., 2005. Identification of high and low responders to lipopolysaccharide in normal subjects: an unbiased approach to identify modulators of innate immunity. Journal of Immunology 175 (4), 2570-2578.

Xu, C., Wang, G., Hao, Y., Zhi, J., Zhang, L., Chang, C., 2011. Correlation analysis between gene expression profile of rat liver tissues and high-fat emulsioninduced nonalcoholic fatty liver. Digestive Diseases and Sciences 56 (8), 22992308.

Yaqoob, P., Calder, P., 1995. Effects of dietary lipid manipulation upon inflammatory mediator production by murine macrophages. Cellular Immunology 163, 120128.

Yeom, K.H., Schonewille, J.Th., Beyen, A.C., 2005. Fatty acid composition of plasma lipids and erythrocytes in adult goats in positive energy balance fed diets containing either olive or corn oil. Small Ruminant Research 58, 25-32.

Zhao, G., Etherton, T.D., Martin, K.R., Vanden Heuvel, J.P., Gillies, P.J., West, S.G., KrisEtherton, P.M., 2005. Anti-inflammatory effects of polyunsaturated fatty acids in THP-1 cells. Biochemical and Biophysical Research Communications 336, 909-917. 